\title{
On-Site Primary Care and Mental Health Services in Outpatient Drug Abuse Treatment Units
}

\author{
Peter D. Friedmann, M.D., M.P.H. \\ Jeffrey A. Alexander, Ph.D. \\ Lei Jin, M.A. \\ Thomas A. D'Aunno, Ph.D.
}

\begin{abstract}
Providing health services to drug abuse treatment clients improves their outcomes. Using data from a 1995 national survey of 597 outpatient drug abuse treatment units, this article examines the relationship between these units'organizational features and the degree to which they provided onsite primary care and mental health services. In two-stage models, Joint Commission on Accreditation of Healthcare Organizations-certified and methadone programs delivered more on-site primary care services. Units affiliated with mental health centers provided more on-site mental health services but less direct medical care. Units with more dual-diagnosis clients provided more on-site mental health but fewer on-site HIV/AIDS treatment services. Organizational features appear to influence the degree to which health services are incorporated into drug abuse treatment. Fully integrated care might be an unattainable ideal for many such organizations, but quality improvement across the treatment system might increase the reliability of clients' access to health services.
\end{abstract}

The majority of substance abuse treatment in the United States occurs in the outpatient setting. ${ }^{1}$ The major treatment modalities used in outpatient substance abuse treatment programs include drug-free counseling and methadone pharmacotherapy. While the provision of a pharmacological treatment for addiction is a major feature distinguishing methadone from drug-free or abstinencebased programs, most programs provide a common core of supportive group or individual counseling, with varied delivery of secondary treatment modalities and ancillary services. ${ }^{2,3}$ Primary care and mental health services are important ancillary services in these programs because they improve clients' retention in treatment programs and substance abuse treatment outcomes. ${ }^{4-8}$ Comprehensive management of substance-related medical and mental health problems also improves the overall health and functioning of recovering persons., ${ }^{9,10}$

Address correspondence to Peter D. Friedmann, M.D., M.P.H., Assistant Professor of Medicine, Section of General Internal Medicine, University of Chicago, 5841 South Maryland Avenue (MC2007), Chicago, IL 60637; e-mail: pfriedma@medicine.bsd.uchicago.edu.

Jeffrey A. Alexander, Ph.D., is a professor of health management and policy in the School of Public Health, University of Michigan.

Lei Jin, M.A., is a senior programmer analyst in the Section of General Internal Medicine, University of Chicago.

Thomas A. D'Aunno, Ph.D., is an associate professor of social service administration and health studies at the University of Chicago. 
On-site provision of health services has been shown to improve clients' access to these services. Umbricht-Schneiter, Ginn, Pabst, et al. ${ }^{11}$ randomly assigned methadone clients to receive medical care through an on-site program or through a referral agreement with a local clinic. Despite efforts to make the referral as effective as possible, only $35 \%$ of the referral group received medical care, compared to $92 \%$ of the on-site group. Substance abuse treatment clients have difficulty keeping referral appointments outside of the treatment unit for many reasons including disorganized lifestyles, prior negative interactions with the mainstream health system, lack of insurance, transportation and other access problems, and rules about the number of required therapy hours. On-site location of services ("one-stop shopping") effectively overcomes these barriers ${ }^{12,13}$ and is recommended for clients in treatment. ${ }^{14,15}$ Nonetheless, provision of comprehensive services to drug abuse treatment clients declined in the early $1990 \mathrm{~s}^{2,3,16}$

Because outside referral for health services has limited effectiveness, ${ }^{1}$ it is important for behavioral health care policymakers and administrators to understand the extent to which American drug treatment units provide on-site health services and the organizational conditions under which more integrated arrangements develop. Given diverse organizational goals, resource constraints, external regulations, and multiple client needs, what organizational influences determine the extent to which a unit produces on-site primary care and mental health services for its clients? Such understanding could inform the development of future initiatives and systems of care to improve addicted clients' reliable access to comprehensive health services.

This article assumes that the values and environment of drug abuse treatment units determine their structure and operations including delivery of integrated health services. ${ }^{17,18}$ Because the influences of such services on on-site delivery are necessarily complex, this article applies ideas drawn from diverse perspectives in organizational theory to describe how organizational goals, resources, mandates, and client contingencies affect service integration and innovation. The relationship between organizational characteristics and the degree of on-site provision of primary care and mental health services is examined using data from a nationally representative sample of outpatient substance abuse treatment units in 1995.

\section{Organizational Goals}

Despite their empirical relationship to improved treatment outcomes, primary care and mental health services vary in their centrality to the core function of these organizations-rehabilitation of drug-abusing clients. Whether a unit values holistic improvement of addicted clients' health is, in part, a reflection of its other conflicting or consonant values, the people within the organization, and its environment. ${ }^{19}$ To the extent that a particular substance abuse treatment unit values the amelioration of its clients' physical and behavioral problems as among its most important goals, it will expend resources to ensure reliable delivery of these health services to a greater degree. For example, units in which physical health is an important goal for treatment should go to greater lengths to provide medical services than should units in which physical health is less important. Explanation of the extent to which a drug abuse treatment organization addresses the physical and mental health of its clients must account for institutional factors related to its goals.

The goals of a drug abuse treatment unit often reflect those of a parent organization. Although units owned and operated on a for-profit basis have diverse priorities, profit seeking is a goal that separates such organizations from public or not-for-profit entities. ${ }^{20}$ To the extent that provision of health services is costly and could lessen investors' return, ${ }^{21}$ for-profit units might place a weaker priority on such services than would public or not-for-profit units. In addition, public or not-for-profit units might have a stronger public health orientation. Units owned by for-profit entities, therefore, might circumscribe their priorities to a greater extent than would publicly owned units. Such narrowing of objectives might exclude improvement of clients' physical and mental health from the purview of for-profit units. Conversely, affiliation with a hospital or mental health center might broaden organizational priorities beyond drug abuse rehabilitation to be more consonant with the mission and 
expertise of the parent organization. Such affiliations might cause units to provide on-site medical and mental health services to a greater degree.

Staff mix also may affect organizational priorities. Although recovering counselors have duties and expectations similar to those of degreed professional counselors, ${ }^{22,23}$ units with a greater proportion of recovering staff might give amelioration of medical and mental health problems less priority than would units with more professional staff. ${ }^{24,25}$ In addition to differences in organizational goals, units that rely more on recovering staff might be less able to provide on-site mental health and medical services. ${ }^{16}$ Such units might incorporate ancillary health services into internal programming to a lesser extent.

Finally, a strong quality orientation, such as that seen in units certified by the Joint Commission on Accreditation of Healthcare Organizations (JCAHO), also may influence provision of on-site services. ${ }^{13,26}$ To the extent that overall quality of health care is an important priority, a drug abuse treatment unit might provide more clients with reliable, integrated health services.

\section{Resources}

Regardless of a treatment unit's priorities, uncertainty in its resource environment may cause procurement of resources essential to the survival of its core function, drug rehabilitation, to supersede any emphasis on comprehensiveness. ${ }^{27}$ Drug abuse treatment organizations are relatively weak actors in their local environments and are highly dependent on external sources for funding, clients, and legitimacy. ${ }^{28}$ These units are acutely aware of their liabilities and of external threats to their survival. Therefore, units with lower total revenues, younger age, and smaller size will be more insecure about their survival and will provide fewer on-site health services. For example, programs subject to the liabilities of "newness" and "smallness,"29,30 or those faced with external threats such as greater competition for referrals and government funding, might be unlikely to develop asset-inflexible onsite health programs. ${ }^{13}$ Conversely, larger units and those with greater revenues might be more likely to institute innovative comprehensive service programs because they face less uncertainty about their survival and have greater "slack" resources. 31

Availability of resources specific to direct provision of the ancillary health service, such as the local density of primary care physicians and psychiatrists, also will affect a unit's propensity to directly provide on-site health services. For units in communities with an abundance of physicians, the greater availability and lower cost of part- or full-time physician staff might make on-site programming more feasible. Units located in communities with many hospitals might be able to make referral linkages more easily and at less cost than would units in communities with fewer hospitals. Units in such communities might develop on-site health programs to a lesser degree.

\section{Mandates}

Mandates to reliably provide health services often will force a unit to deliver primary care and mental health services directly to obtain legitimacy and funding from important entities in its environment. Many states, for example, mandate delivery of physical examinations and tuberculosis screening to methadone clients as requirements of licensure. ${ }^{32}$ Funding specific to HIV-infected clients also may require that these clients receive appropriate health and social services. Units might comply with these mandates because they form a legal and financial foundation for the organizations' existence. ${ }^{33}$

\section{Client Characteristics}

Finally, a drug abuse treatment unit might provide more on-site health services in response to clients' greater health problems and service needs. Thus, clients' health needs represent task contingencies to which units adapt their product lines. ${ }^{27}$ Therefore, these analyses examine client characteristics possibly indicative of greater need for health services within the population served by the 
treatment unit including clients' age, gender, and race; type of drug abuse; and the prevalence of HIV infection, comorbid mental illness, and unemployment. ${ }^{16}$

\section{Methods}

\section{Sample}

This study uses cross-sectional data from the 1995 wave of the National Drug Abuse Treatment System Survey (DATSS), a panel study of America's outpatient drug abuse treatment units. ${ }^{34}$ An eligible outpatient drug abuse treatment unit was defined as a physical facility with more than half of its resources dedicated to nonresidential treatment of drug abuse problems. Veterans Administration and correctional facility programs were excluded.

From the 1988 and 1990 waves of the DATSS, 429 programs remained eligible; interviews were obtained in $376(88 \%)$. In addition to programs recontacted from the earlier waves, the sample was supplemented to provide unbiased representation of the treatment unit population in 1995. The sampling frame for the cross-sectional sample was a subset of the 1994-1995 National Frame of Substance Abuse Treatment Programs (NFSATP), the most complete listing available of the nation's drug abuse treatment units, a total of 32,927 unduplicated programs. The NFSATP is the integration of the Substance Abuse and Mental Health Administration's National Facilities Register database (13,745 listings), the frame for the 1992 National Drug and Alcoholism Treatment Unit Survey (11,105 programs), the 1994 American Hospital Association Survey (5,057 listings), the 1994 Food and Drug Administration List of Licensed Methadone Programs (404 outpatient programs), and the Business Database from Survey Sampling Inc. (2,616 programs). ${ }^{35}$

As in previous waves of the DATSS, the sample frame was stratified by treatment modality (methadone or drug free), ownership (private for-profit, private not-for-profit, or public) and affiliation (hospital, mental health center, or freestanding). For the 1995 supplementation, the frame was stratified on these factors to ensure adequate numbers of private, nonhospital, nonmethadone units. A random sample of 972 programs was screened by telephone; only 270 were eligible, and 231 $(86 \%)$ agreed to be interviewed. All told, a nationally representative, stratified sample of 699 units was contacted in 1995, and $618(88 \%)$ participated. The current analysis examines the 597 units with data regarding the provision of primary care and mental health services.*

\section{Data Collection}

Each unit's administrative director and clinical supervisor completed telephone interviews. Directors provided information about the unit's ownership, affiliations, environment, finances, and managed care arrangements. Supervisors provided information about clients, staff, services provided, and the mechanism used to provide service. All information was collected for the programs' most recent complete fiscal years, except where noted.

The study team at the University of Michigan's Institute for Social Research (ISR) employed several procedures to ensure high-quality, valid, reliable telephone survey data. ${ }^{36}$ In preparation for the study, the study team performed case studies to inform survey development, pretested the survey twice with national random samples of more than 40 respondents, extensively trained the experienced ISR telephone interviewers about the details of this study, and mailed each unit director a cover letter explaining the study. During data collection, the investigators guaranteed confidentiality and feedback reports to respondents, conducted live checks on the interviewers, and used frequent

\footnotetext{
*In the multivariate analyses of on-site primary care and mental health service provision, listwise deletion of missing values reduced the sample size from 597 possible cases to 501 cases. Service availability and on-site provision in the deleted cases were compared using chi-square and independent sample $t$ tests, respectively. There were no significant differences in the availability or provision of these services between the deleted cases and those included in the analyses.
} 
probes and follow-up questions. At the completion of data collection, the investigators conducted extensive checks for consistency in responses within and between each section of the survey as well as between the different waves of the survey. These checks indicated high levels of consistency. To further verify the validity of the unit-level data collection methods used in the DATSS, the investigators compared the 1990 DATSS data to discharge record abstracts from the 1990 Drug Services Research Study (DSRS). ${ }^{37}$ The DSRS abstracted the charts of 2,200 drug treatment clients discharged in 1990. The comparison of the DATSS and DSRS demonstrated similarity in several key measures including average treatment duration (6.1 months vs. 6.0 months, respectively), mean number of current clients (100.3 vs. 100.9), and number of paid treatment staff members ( $8.2 \mathrm{vs.}$ 8.2). The concordance of the DATSS measurements with chart-based data provides strong evidence of their validity in the current study.

\section{Dependent Variables}

Dependent variables reflected the degree to which a drug abuse treatment unit provided on-site medical and mental health services to its clients. For each of five service categories (physical examinations, routine medical care, tuberculosis screening, treatment for acute HIV/AIDS conditions, and treatment for mental health problems), clinical supervisors were asked whether the particular service was available to clients either directly from the unit staff or through arrangements with other providers. These yes/no responses are the dependent variables for the first-stage models.

For each available service category, the clinical supervisor next indicated the percentage of services provided by an outside source. By subtracting this response from $100 \%$, the second-stage dependent variables were created-percentage of services provided by an inside or on-site source. Thus, this article treats the terms inside and on-site as synonymous. On-site refers to the location of the services (inside) and not the employment status (full-time, part-time, or consultant) of the staff members providing them. However, analyses not shown demonstrated strong associations between the unit's staffing of professionals qualified to deliver these services (e.g., physicians, nurses) and their on-site delivery (e.g., routine medical care).

\section{Independent Variables}

The analyses model the relationship between organizational factors and on-site provision of physical examinations, routine medical care, tuberculosis screening, treatment for acute HIV/AIDS conditions, and treatment for mental health problems. Table 1 displays the definitions, source information, and weighted descriptive statistics for these variables. Extensive checks revealed no multicollinearity between candidate variables.

\section{Statistical Methods}

The unit of analysis was the treatment unit. For all analyses, sample weights compensated for the stratified sampling design. ${ }^{35}$ To examine the effect of the organizational factors on the degree of on-site service provision, separate model estimates and significance tests were generated for each service (five separate models) using a two-part estimation procedure to correct for sample selection bias. ${ }^{38}$ Because information about on-site service provision is available only for those units in which the service is available, selection bias might result if systematic differences between units that do and do not offer ancillary health services were significantly associated with factors correlated with the degree of on-site care. For example, if unit age were associated with both the availability of routine medical care in the unit and the degree to which the unit provides on-site routine medical care, then specification error would bias any single-stage estimation only in those units for which there was information on on-site care. Therefore, the analyses employed two-stage models that first performed 
Table 1

Explanatory Variables: Definitions and Descriptive Statistics

\begin{tabular}{|c|c|c|c|c|}
\hline Variable & Description & Range & Mean & $S D$ \\
\hline \multicolumn{5}{|l|}{ Organizational goals } \\
\hline \multicolumn{5}{|l|}{ Ownership } \\
\hline Private not-for-profit & Unit was private nonprofit, private for-profit, & $0-1$ & .16 & .37 \\
\hline Private for-profit & $\begin{array}{l}\text { or publicly owned; responses dummy- } \\
\text { coded }(0=n o, 1=y e s) \text { with public } \\
\text { ownership as the referent }\end{array}$ & $0-1$ & .52 & .50 \\
\hline \multicolumn{5}{|l|}{ Affiliation } \\
\hline Mental health center & Unit had any affiliation with a hospital or & $0-1$ & .23 & .42 \\
\hline Hospital & $\begin{array}{l}\text { community mental health center; } \\
\text { responses dummy-coded }(0=n o, 1=y e s) \\
\text { with "other or no affiliation" as referent. }\end{array}$ & $0-1$ & .16 & .37 \\
\hline $\begin{array}{l}\text { Percentage recovering } \\
\text { staff }\end{array}$ & $\begin{array}{l}\text { Percentage of staff in recovery from drug } \\
\text { abuse. }\end{array}$ & $0-100$ & 30 & 26 \\
\hline Positive physical health & $\begin{array}{l}\text { Supervisor's agreement that "Positive } \\
\text { physical health is an important goal for } \\
\text { treatment" on a 5-point Likert scale } \\
\text { (dichotomized as } 1=\text { strongly agree vs. } \\
0=\text { others) }\end{array}$ & $0-1$ & .85 & .36 \\
\hline JCAHO accreditation & $\begin{array}{l}\text { Unit had JCAHO accreditation }(0=n o, \\
1=\text { yes })\end{array}$ & $0-1$ & .22 & .41 \\
\hline
\end{tabular}

Resources

Total revenue

Total revenue in thousands of dollars in

$0-10,832 \quad 394 \quad 668$ previous fiscal year

Unit size

Total number of clients in the previous fiscal year

$10-10,084537 \quad 733$

Number of years unit has been in operation

Unit age

Competition for:

Referrals

Director's reports of the extent of

$0-42 \quad 13 \quad 9$

competition with other treatment units

Government funding for client referrals and for funding from government sources ( $1=$ no extent to $5=a$ very great extent)

Per 1 million population:

Number of primary care physicians

From 1993 area resource file and 1990 census data, ratio of number of

Number of psychiatrists

Number of hospitals

Number of psychiatric hospitals

primary care physicians, psychiatrists, medical hospitals, and psychiatric

hospitals, respectively, per 1 million

local population; data are linked using

FIPS codes, usually at the county level

$\begin{array}{ccc}0-2,812 & 756 & 469 \\ 0-1,183 & 158 & 220 \\ 0-366 & 31 & 36 \\ & & \\ 0-115 & 2 & 8\end{array}$




\begin{tabular}{|c|c|c|c|c|}
\hline Variable & Description & Range & Mean & $S D$ \\
\hline \multicolumn{5}{|l|}{ Mandates } \\
\hline Methadone treatment & $\begin{array}{l}\text { Unit provided methadone treatment }(0=n o, \\
1=\text { yes })\end{array}$ & $0-1$ & .14 & .35 \\
\hline HIV-related grants & $\begin{array}{l}\text { Did the unit receive any funding that was } \\
\text { specifically designated for use with HIV- } \\
\text { positive clients in the most recent complete } \\
\text { fiscal year? }(0=n o, 1=y e s)\end{array}$ & $0-1$ & .05 & .23 \\
\hline \multicolumn{5}{|l|}{ Client characteristics } \\
\hline Mean client age & Estimated mean age of clients in years & $8-69$ & 32 & 6 \\
\hline Percentage women clients & Percentage of women clients & $0-100$ & 36 & 20 \\
\hline $\begin{array}{l}\text { Percentage dual-diagnosis } \\
\text { clients }\end{array}$ & $\begin{array}{l}\text { Percentage of clients with both mental } \\
\text { health and substance abuse problems }\end{array}$ & $0-100$ & 29 & 25 \\
\hline $\begin{array}{l}\text { Percentage HIV-infected } \\
\text { clients }\end{array}$ & $\begin{array}{l}\text { Percentage of clients who have tested positive } \\
\text { for HIV }\end{array}$ & $0-67$ & 5 & 9 \\
\hline $\begin{array}{l}\text { Percentage unemployed } \\
\text { clients }\end{array}$ & Percentage of unemployed clients & $0-100$ & 43 & 28 \\
\hline Percentage Black clients & Percentage of African American clients & $0-100$ & 22 & 25 \\
\hline
\end{tabular}

NOTE: Descriptive statistics are weighted to be nationally representative. JCAHO = Joint Commission on Accreditation of Healthcare Organizations; FIPS = Federal Information Processing Standard.

probit regression in the full sample to estimate the likelihood of the service being available in the unit. This analysis generated a selection bias parameter (lambda) that summarized information about the factors that influenced service availability (yes/no) and, consequently, observation of the dependent variable in the second stage. ${ }^{39}$ The selection parameter was then included in a secondstage generalized linear model of the logit of the proportion of clients who received the service onsite (conditional on having observed the dependent variable), with variances adjusted for overdispersion. ${ }^{40-42}$ All significance tests were two-tailed.

\section{Results}

Using sampling weights to extrapolate from the 597 units in the sample, $16 \%$ of outpatient addiction treatment units in the United States were private for-profit organizations, 52\% were not-forprofit, and $32 \%$ were publicly owned in 1995 (Table 1). In addition, $16 \%$ of the units were affiliated with hospitals, $23 \%$ were affiliated with mental health centers, and $61 \%$ were freestanding or otherwise affiliated. These programs served a mean ( \pm standard deviation) of $537 \pm 733$ clients in the 1994 fiscal year and were in operation $13 \pm 9$ years. Methadone was available in $14 \%$ of the units, and $22 \%$ were JCAHO accredited.

Nationwide, primary care and mental health services were available in the majority of drug abuse treatment units through either referral or on-site programming (Table 2). On-site health services were available in less than half of the units nationwide. For example, on-site physical examinations were available in $48 \%$ of the 479 units with the service available or $38 \%$ of units overall. Similarly, 


\section{Table 2}

Dependent Variables: On-Site Primary Care and Mental Health Services

\begin{tabular}{lccc}
\hline Service & $\begin{array}{c}\text { Service Available } \\
\text { On-Site or via Referral }\end{array}$ & $\begin{array}{c}\text { Service Available } \\
\text { On-Site }^{\mathrm{b}}\end{array}$ & $\begin{array}{c}\text { Where Service Available, } \\
\text { Percentage of Services }^{\text {Provided On-Site }}\end{array}$ \\
\hline Physical examinations & $479(80)$ & $228(48)$ & $28 \pm 39$ \\
Routine medical care & $366(61)$ & $145(40)$ & $18 \pm 32$ \\
Tuberculosis screening & $347(58)$ & $151(44)$ & $30 \pm 42$ \\
HIV/AIDS treatment & $123(21)$ & $36(30)$ & $4 \pm 11$ \\
Mental health treatment & $519(87)$ & $336(65)$ & $19 \pm 26$ \\
\hline
\end{tabular}

NOTE: Descriptive statistics are weighted to be nationally representative. Weighted percentages are in parentheses.
a. $n s$ and percentages.
b. $n s$ and percentages of units with service available.
c. means $\pm S D$ s.

$24 \%$ of units nationwide delivered on-site routine medical care, $25 \%$ delivered on-site tuberculosis screening, $6 \%$ delivered acute HIV/AIDS treatment, and 56\% delivered on-site mental health services. In units where primary care or mental health services were available at all, fewer than onethird of services were delivered on-site (Table 2).

\section{Availability of Services}

The first-stage analysis modeled the availability of primary care and mental health services in the units either on-site or through an arrangement with outside providers. In general, units that had primary care services available had public rather than private ownership, hospital or freestanding affiliation rather than affiliation with mental health centers, greater total revenue, smaller unit size, methadone programs, and more unemployed clients (Table 3). HIV treatment was more available in units with less competition for referrals, more competition for government funding, methadone treatment modalities, and more HIV-infected clients. Mental health services were available either on-site or by referral in units with public ownership, greater total revenue, fewer psychiatrists in the local community, nonmethadone treatment modalities, more dual-diagnosis clients, and older clienteles.

\section{On-Site Provision of Services}

The second stage of the model examined the degree of on-site provision of primary care and mental health services (Table 4). For-profit ownership, hospital affiliation, and reporting that physical health was a goal of treatment did not influence on-site delivery of any health service. Overall, units that provided more on-site primary health care services lacked mental health center affiliations, were JCAHO certified, reported less competition for government funding, and had methadone treatment available. Fewer on-site HIV treatment services were provided in private not-for-profit units, units with smaller total revenues, and units that served more dually diagnosed clients. Mental health care was delivered on-site to a greater degree in units with mental health center affiliations, fewer recovering staff, greater total revenues, and more years in operation as well as in units that served greater percentages of dually diagnosed, employed, and female clients. 


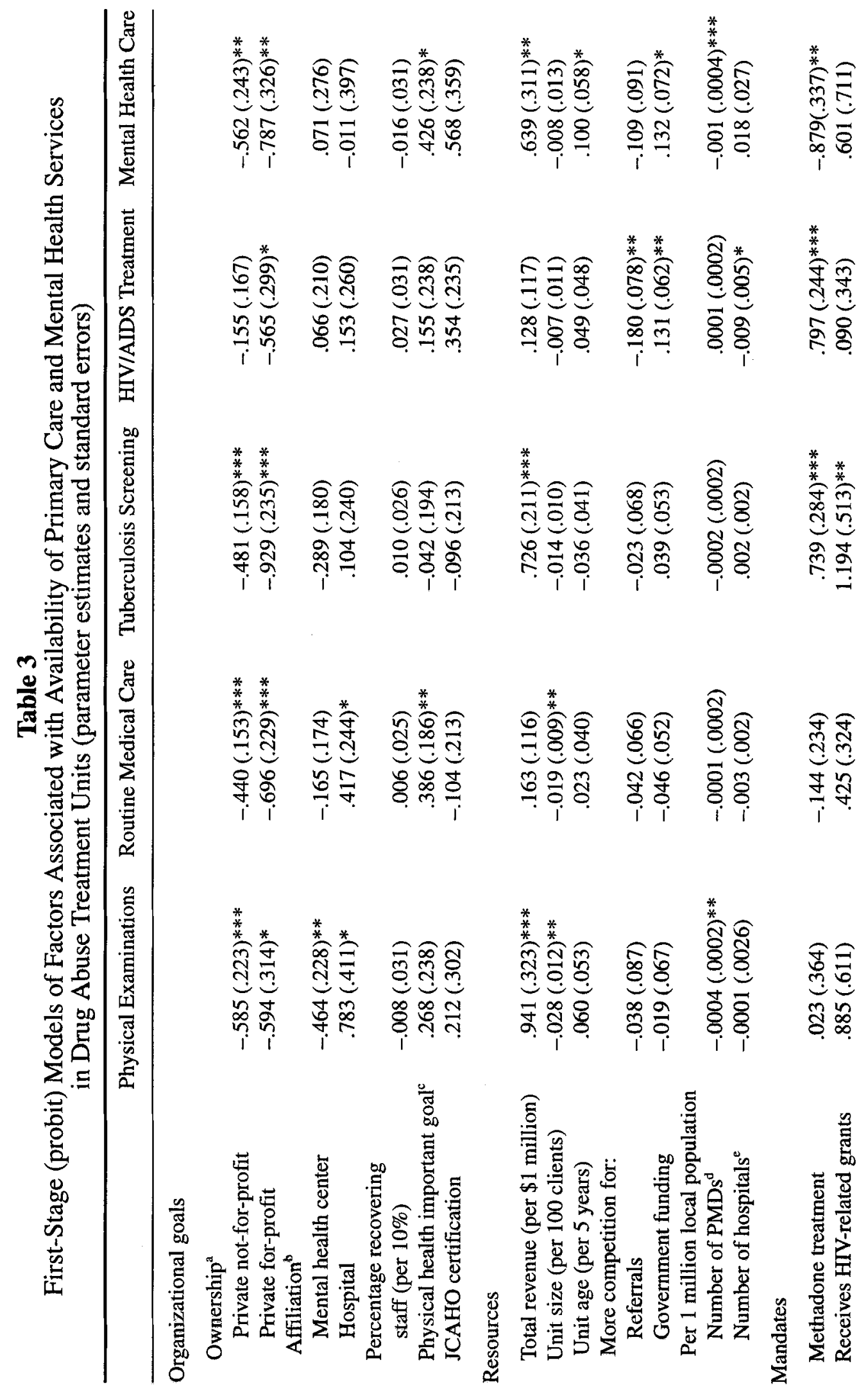




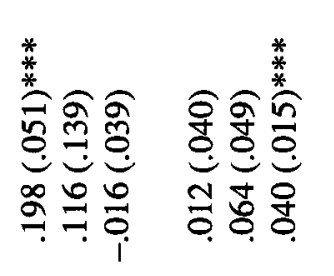

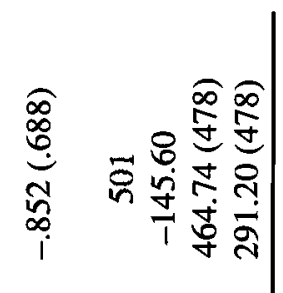

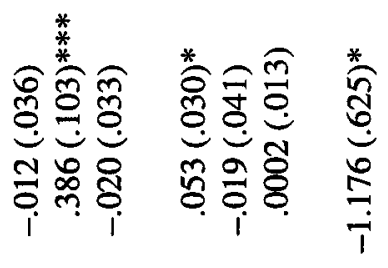

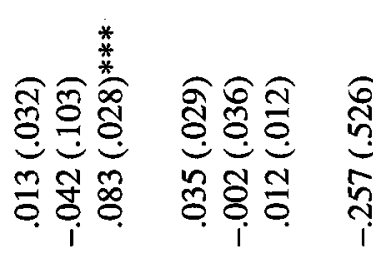

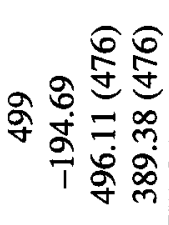

气

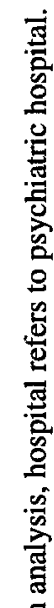

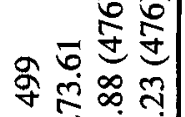

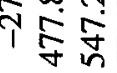

:

它 它

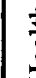

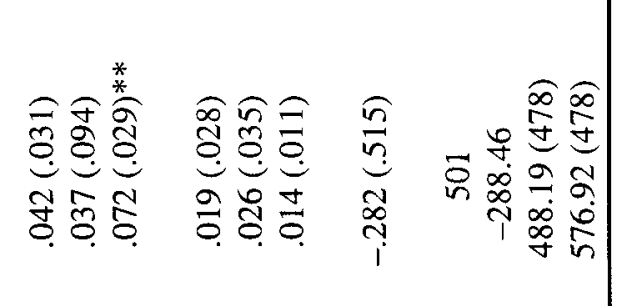

㗊

芯递

호․

营窵

尝

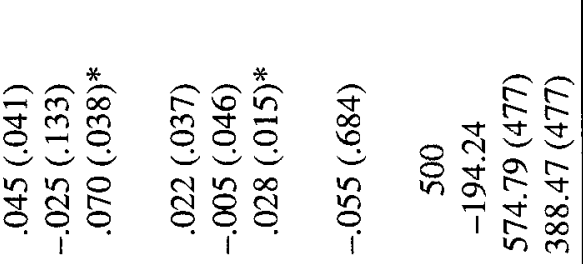

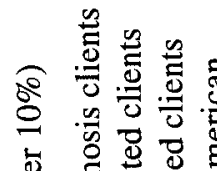

㐫

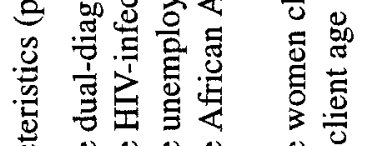

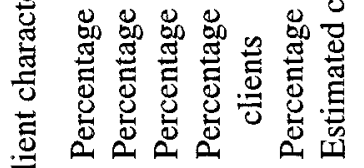

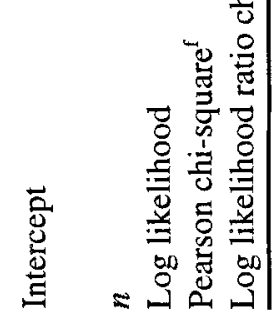

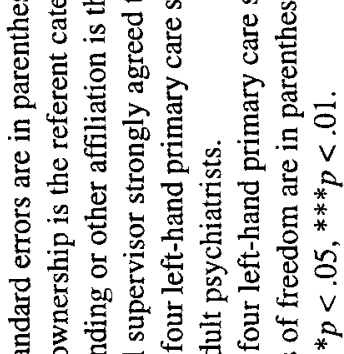

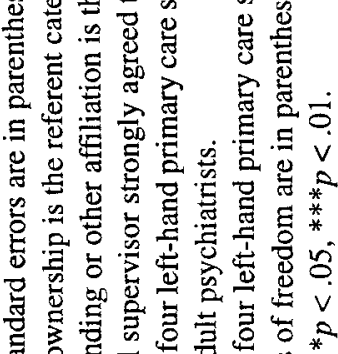

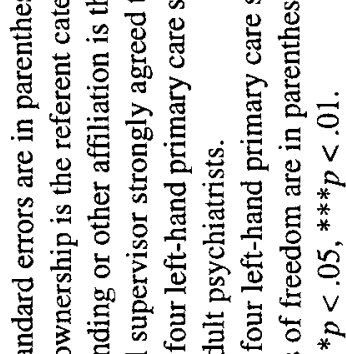

它芯造.

要焉

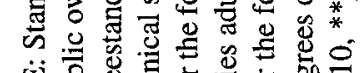

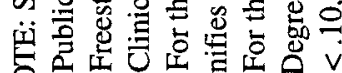




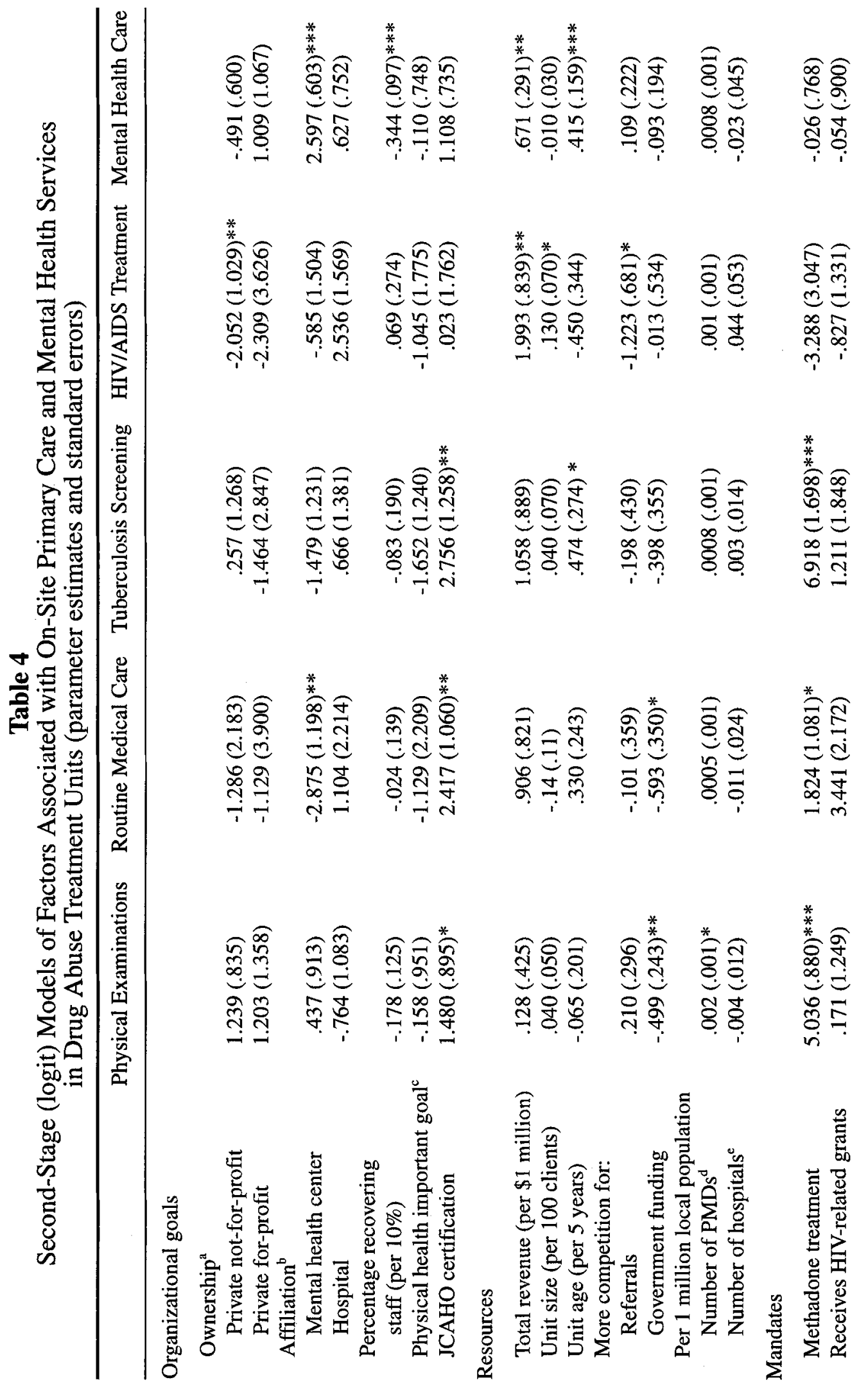




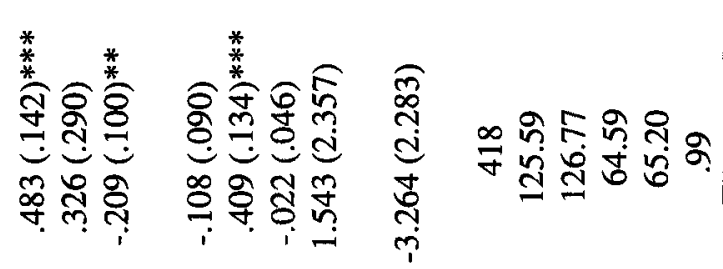

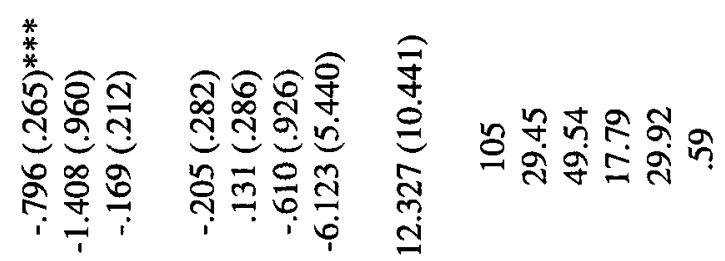

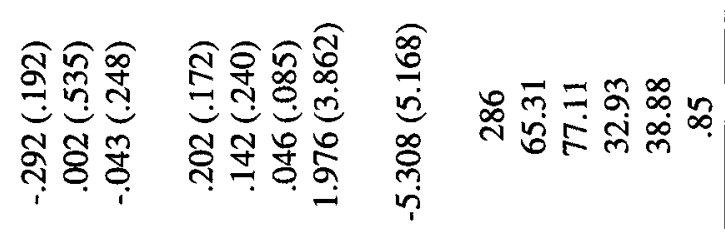

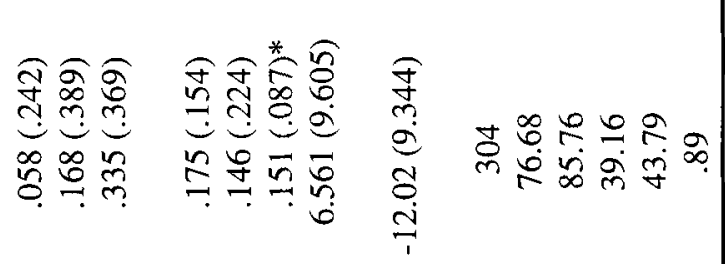

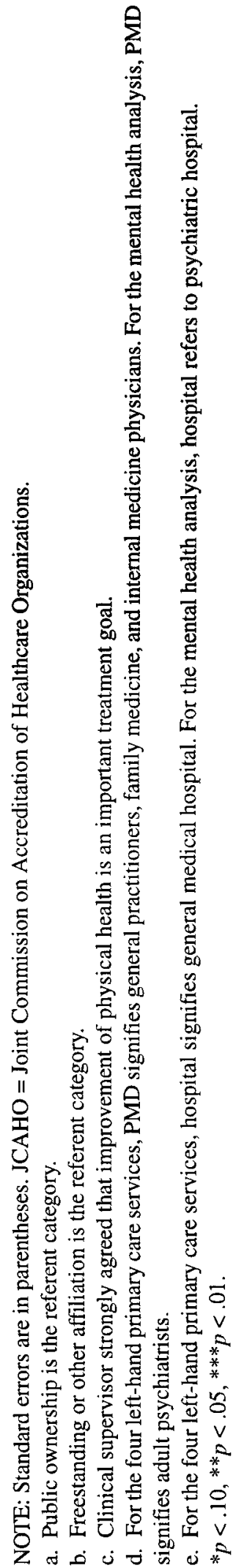

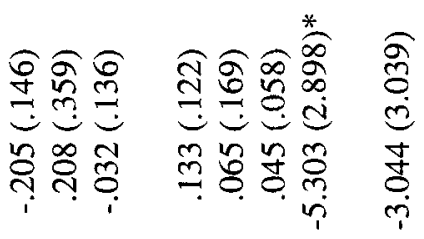

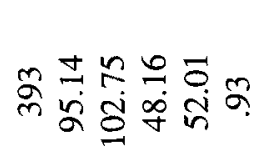
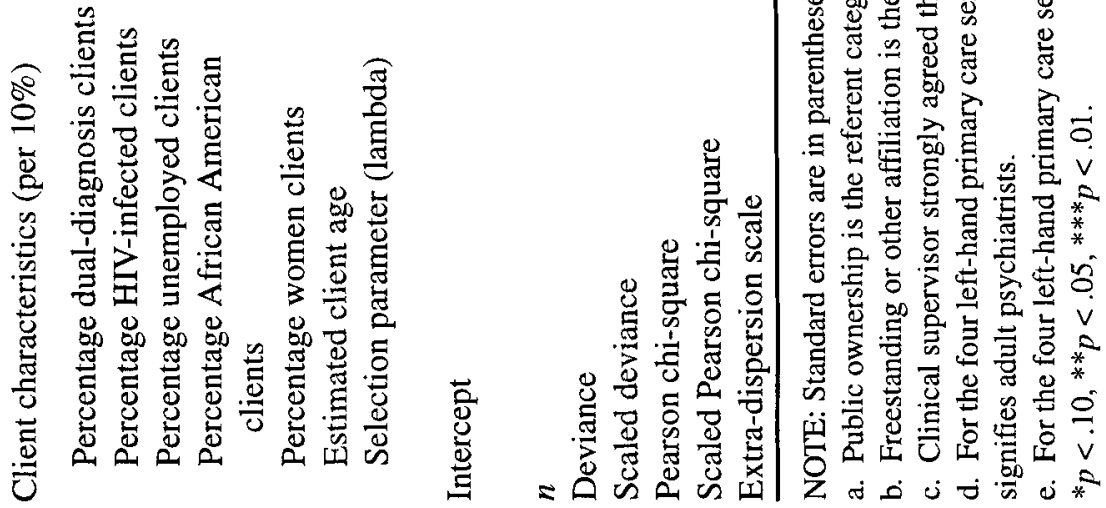


\section{Discussion}

Organizational goals exerted a modest influence on the degree to which drug abuse treatment units provided on-site primary care and mental health services. These services were less available in private for-profit and not-for-profit units than in public units in the first-stage models, but ownership status exerted little effect on the degree of on-site provision in the second-stage models. ${ }^{43}$ Units affiliated with mental health centers provided on-site mental health services to a greater degree but provided on-site routine medical care to a lesser degree. This finding suggests that units often provide on-site services in accordance with the organizational priorities and expertise of their affiliates and that it might be unrealistic to expect units to develop integrated programs in multiple areas requiring diverse expertise and staffing.

Regarding staffing, the results affirm the findings of other studies that mental health services are delivered less reliably in programs with more recovering staff. ${ }^{24,25}$ None of the resource variables modified this effect, suggesting that greater fiscal constraints in units with more recovering staff did not explain this result. A greater proportion of recovering staff might mean that such programs lack the professional expertise to provide mental health services internally. ${ }^{16,44}$ Alternatively, it might indicate that the predominant organizational ideology views the mental health paradigm as incongruous with addiction treatment. ${ }^{45}$

The assertion of physical health as an important treatment goal had surprisingly little relationship to either service availability or on-site provision of primary care, but the small number of units whose supervisors did not strongly agree with this assertion limited discriminatory power. However, a commitment to high-quality care, as manifested by JCAHO accreditation, was associated with greater provision of on-site ancillary health services. ${ }^{13,26}$ This finding suggests that an increased emphasis on quality across the substance abuse treatment system might increase the reliable provision of primary care and mental health services as well.

The results showed surprisingly little effect of resources on the degree of on-site health service provision. Units with greater total revenues delivered more on-site HIV treatment and mental health services but not more on-site physical examinations, routine medical care, or tuberculosis screening. Unit age and size, other manifestations of unit stability and slack resources, ${ }^{46}$ also showed only minimal effects.

With regard to mandates, methadone availability augmented on-site provision of most primary care services, ${ }^{47}$ while receipt of HIV-specific grants showed no effects. Federal and state mandates about the provision of health services to methadone clients, ${ }^{15,32}$ perhaps in combination with the implicit acceptance of neurobiological models of addiction within methadone units, might have facilitated methadone providers' acceptance of on-site biomedical services.

These analyses have at least three important limitations. First, this cross-sectional study cannot determine the causal direction between the organizational factors and provision of on-site services. Second, clinical supervisors were not given explicit definitions for each of the service categories. Ill-defined boundaries between service categories (e.g., tuberculosis screening and routine medical care) and across drug abuse treatment services (e.g., drug abuse counseling and mental health treatment) might have spuriously increased supervisors' estimates of the percentages of services delivered on-site. Third, only unit-level reports of the proportions of on-site services were available. Although it is unknown whether clinical supervisors' reports about such matters are accurate, they probably reflect the strength of the units' efforts to provide on-site services.

\section{Implications for Behavioral Health Services Delivery}

Although fully integrated primary care, mental health, and substance abuse treatment reliably brings critical services to the drug abuse treatment population, on-site primary care services are available in less than $40 \%$ of drug abuse treatment units, and less than $60 \%$ of programs provide onsite mental health services. Gathering under one roof the diverse expertise and staff that are neces- 
sary to provide fully integrated primary medical and mental health care, not to mention other important ancillary services, presents a great challenge to most such units. Despite the reliability of on-site care as a delivery mechanism, ${ }^{11}$ one-stop shopping in drug abuse treatment units might be an unattainable ideal. Improvement of referral linkages, including better communication between treatment programs and health care providers, might be a more feasible alternative.$^{12,13}$ In this regard, a consistent emphasis on quality improvement across the drug abuse treatment system might prove more effective at promoting drug treatment clients' access to health care than would intermittent initiatives advocating provision of individual health services.

\section{Acknowledgments}

This research was supported by Grants 1K08-DA00320 and 5R01-DA03272 from the National Institute on Drug Abuse (NIDA). The views expressed here are those of the authors and do not necessarily reflect those of NIDA. This research was presented at the annual meeting of the American Public Health Association, Indianapolis, IN, November 12, 1997. The authors thank Christy Harris Lemak and Barbara Lamar for their counsel and data management.

\section{References}

1. Gerstein DR, Harwood HJ (Eds.): Treatment of Drug Problems: A Study of the Evolution, Effectiveness and Financing of Public and Private Drug Treatment Systems. Vol. 1. Report of the Committee for the Substance Abuse Coverage Study, Division of Health Care Services, Institute of Medicine. Washington, DC: National Academy Press. 1990.

2. Etheridge RM, Craddock SG, Dunteman GH, et al.: Client services in two national studies of community-based drug abuse treatment programs. Journal of Substance Abuse 1995; 7:9-26.

3. Etheridge RM, Hubbard RL, Anderson J, et al.: Treatment structure and program services in the Drug Abuse Treatment Outcome Study (DATOS). Psychology of Addictive Behaviors 1997; 11:244-260

4. McCaughrin WC, Price RH: Effective outpatient drug treatment organizations: Program features and selection effects. International Journal of the Addictions 1992; 27:1335-1358.

5. McLellan AT, Arndt IO, Metzger DS, et al.: The effects of psychosocial services in substance abuse treatment. Journal of the American Medical Association 1993; 269:1953-1959.

6. McLellan AT, Arndt IO, Woody GE, et al.: Predicting response to alcohol and drug abuse treatments: Role of psychiatric severity. Archives of General Psychiatry 1983; 40:620-625.

7. McLellan AT, Grissom GR, Zanis D, et al.: Problem-service "matching" in addiction treatment. Archives of General Psychiatry 1997; 54:730-735

8. Rounsaville BJ, Kosten TR, Weissman MM, et al.: Prognostic significance of psychopathology in treated opiate addicts. Archives of General Psychiatry 1986; 43:739-745.

9. Stein MD, Samet JA, O'Connor PG: The linkage of primary care services with substance abuse treatment: New opportunities for academic generalists. Journal of General Internal Medicine 1993; 8:106-107.

10. McLellan AT, Hagan TA, Levine M, Gould F, Meyers K, Bencivengo M, Durell J: Supplemental social services improve outcomes in public addiction treatment. Addiction 1998; 93:1489-1499.

11. Umbricht-Schneiter A, Ginn DH, Pabst KM, et al.: Providing medical care to methadone clinic patients: Referral vs. on-site. American Journal of Public Health 1994; 84:207-210.

12. Samet JH, Saitz R, Larson MJ: A case for enhanced linkage of substance abusers to primary medical care. Substance Abuse 1996; 17:181199.

13. D'Aunno TA: Linking substance abuse treatment and primary health care, In: Egertson JA, Fox DM, Leshner AI (Eds.): Treating Drug Users Effectively. Malden, MA: Blackwell, 1997, pp. 311-351.

14. HIV/Linkage Branch, Center for Substance Abuse Treatment: Strengthening the Linkages: Proceedings of the 1992 Secretarial Conference to Link Primary Care, HV, Alcohol, and Drug Abuse Treatment. Washington, DC. U.S. Department of Health and Human Services. 1992.

15. Center for Substance Abuse Treatment: State Methadone Maintenance Treatment Guidelines. DHHS Publication No. (SMA)93-1991. Rockville, MD: Substance Abuse and Mental Health Services Administration, 1993.

16. D'Aunno TA, Vaughn TE: An organizational analysis of service patterns in outpatient drug abuse treatment units. Journal of Substance Abuse 1995; 7:27-42.

17. D'Aunno TA, Price RH: Organizational adaptation to changing environments: Community mental health and drug abuse services. American Behavioral Scientist 1985; 28:669-683.

18. Scott WR: Organizations: Rational, Natural, and Open Systems. Englewood-Cliffs, NJ: Prentice Hall, 1992.

19. Scott WR: Institutions and Organizations. Thousand Oaks, CA: Sage, 1995.

20. Harrigan KR: Strategies for Vertical Integration. Lexington, MA: D. C. Heath, 1983.

21. Kraft MK, Rothbard AB, Hadley TR, et al.: Are supplementary services provided during methadone maintenance really cost-effective? American Journal of Psychiatry 1997; 154:1214-1219

22. Aiken LS, LoSciuto LA, Ausetts MA, et al.: Paraprofessional versus professional drug counselors: Diverse routes to the same role. International Journal of the Addictions 1984; 19:153-173. 
23. LoSciuto LA, Aiken LS, Ausetts MA, et al.: Paraprofessional versus professional drug abuse counselors: Attitudes and expectations of the counselors and their clients. International Journal of the Addictions 1984; 19:233-252.

24. D'Aunno TA: The effectiveness of human service organizations: A comparison of models. In: Hasenfeld Y (Ed.): Human Services as Complex Organizations. Newbury Park, CA: Sage, 1992, pp. 341-361.

25. Berg JE, Andersen S, Alveberg PØ, et al.: Former addicts as members of staff and type of activity offered to drug misusers: Do these factors influence rate of completion? Addiction Research 1997; 5:39-48.

26. McCaughrin WC: The Relationship between Conformity to JCAHO Standards and Organizational Performance. Ph.D. dissertation, University of Michigan, 1991.

27. Thompson J: Organizations in Action. New York: McGraw-Hill, 1967.

28. Hasenfeld Y: Human Service Organizations. Englewood Cliffs, NJ: Prentice Hall, 1983.

29. Baum NAC, Oliver C: Institutional linkages and organizational mortality. Administrative Science Quarterly 1991; 36:187-218.

30. Freeman JH, Carroll GR, Hannan MT: The liability of newness: Age dependence in organizational death rates. American Journal of Sociology 1983; 48:692-710.

31. Damanpour F: Organizational innovation: A meta-analysis of effects of determinants and moderators. Academy of Management Journal 1991; 34:555-590.

32. Institute of Medicine: Federal Regulation of Methadone Treatment. Washington, DC: National Academy Press, 1995.

33. Hasenfeld Y: The nature of human service organizations. In: Hasenfeld Y (Ed.): Human Services as Complex Organizations. Newbury Park, CA: Sage, 1992, pp. 3-23.

34. D'Aunno TA: Treating Drug Abuse in America: Results from a Study of the Outpatient Substance Abuse Treatment System 1988-1995. Ann Arbor: University of Michigan, Institute for Social Research, 1996.

35. Heeringa SG: Outpatient Drug Abuse Treatment Studies: Technical Documentation. Ann Arbor: University of Michigan, Institute for Social Research, Survey Design and Analysis Unit, 1996.

36. Groves RM, Biemer PP, Lyberg LE, et al: Telephone Survey Methodology. New York: John Wiley, 1988.

37. Batten HL, Horgan CH, Prottas JM, et al.: Drug Services Research Survey: Phase I Final Report-Non-correctional Facilities. Waltham, MA: Brandeis University, Institute for Health Policy, 1993.

38. Greene WH: Econometric Analysis. Englewood Cliffs, NJ: Prentice Hall, 1993.

39. Breen R: Regression Models: Censored, Sample Selected, or Truncated Data. Thousand Oaks, CA: Sage, 1996.

40. Breslow NE, Clayton DG: Approximate inference in generalized linear mixed models. Journal of the American Statistical Association 1993; 88:9-25.

41. McCullagh P, Nelder JA: Generalized Linear Models. London: Chapman and Hall, 1989.

42. SAS/STAT User's Guide: Version 6. Cary, NC: SAS Institute, 1990.

43. McLellan AT, Grissom GR, Brill P, et al.: Private substance abuse treatments: Are some programs more effective than others? Journal of Substance Abuse Treatment 1993; 10:243-254.

44. Selwyn PA: Overcoming the mind/body dichotomy in drug abuse treatment. Addiction 1996; 91:11-13.

45. Herman M, Gourevitch MN: Integrating primary care and methadone maintenance treatment: Implementation issues. Journal of Addictive Diseases 1997; 16:91-102.

46. Nohria N, Gulati R: Is slack good or bad for innovation? Academy of Management Joumal 1996; 39:1245-1264.

47. Price RH, Burke AC, D'Aunno TA, et al.: Outpatient drug abuse treatment services 1988: Results of a national survey. In: Pickens RW, Leukefeld CW, Schuster CR (Eds.): Improving Drug Abuse Treatment. DHHS Publication No. (ADM)91-1754. Washington, DC: Government Printing Office, 1991, pp. 63-92.

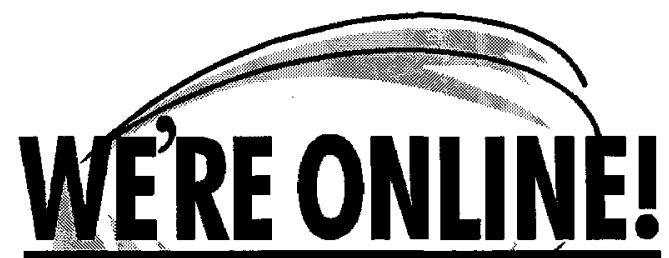

http:/hwww.fmhi.usf.edu/jbhsr/fbhsrmain.html

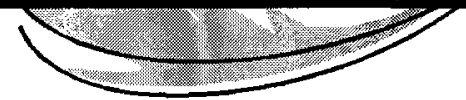

